\title{
Development and Validation of the Beverages and Snacks Questionnaire for Malaysian Schoolchildren (BSQ-C)
}

\author{
Noor Fadzlina Hamid ${ }^{1}$, Nyi Nyi Naing ${ }^{1}$, Rohana Abdul Jalil2, Shigeru Yamamoto ${ }^{3}$ \\ 1 Faculty of Medicine, \\ Universiti Sultan Zainal Abidin, 20400 Kuala Terengganu, Terengganu, Malaysia. \\ 2 Department of Community Medicine, School of Medical Sciences, \\ Universiti Sains Malaysia, 16150 Kubang Kerian, Kelantan, Malaysia. \\ ${ }^{3}$ Asian Nutrition and Food Culture Research Center, \\ Jumonji University, 2-1-28 Sugasawa, Niiza, Saitama 352-8510, Japan. \\ fadzlina@usm.my, syedhatim@unisza.edu.my, rohanajalil@usm.my, yamamotoshigeru426@gmail.com \\ Tel: +60125325468
}

\begin{abstract}
The intake of sugar-sweetened beverages (SSBs) and snacks have changed and has associated with weight gain in children. However, it is challenging to measure the consumption of SSBs and snacks due to the limitation of existing tools. Aimed for this study was to develop and validate the beverages and snacks questionnaire for schoolchildren (BSQ-C). In testing for internal consistency, the value of Cronbach's alpha indicated that more than 0.70 is considered an acceptable internal consistency. In conclusion, the BSQ-C developed is valid and reliable to measure the pattern and behaviour of SSBs and snacks intake among schoolchildren.
\end{abstract}

Keywords: Beverages and snacks questionnaire (BSQ-C); Sugar-sweetened beverages (SSBs); Snacks; Reliability

eISSN: 2398-4287 @ 2019. The Authors. It is published for AMER ABRA cE-Bs by e-International Publishing House, Ltd., UK. This is an open-access article under the CC BYNC-ND license (http://creativecommons.org/licenses/by-nc-nd/4.0/). Peer-review under responsibility of AMER (Association of Malaysian Environment-Behaviour Researchers), ABRA (Association of Behavioural Researchers on Asians) and cE-Bs (Centre for Environment-Behaviour Studies), Faculty of Architecture, Planning \& Surveying, Universiti Teknologi MARA, Malaysia.

DOI: https://doi.org/10.21834/e-bpj.v4i12.1909

\subsection{Introduction}

Malnutrition is related to unhealthy dietary patterns. Lately, there is growing evidence about the types of food and beverages consumed as snacks, and the amount of energy contributed by snacking habits. (Dunford \& Popkin, 2018). Alterations in the composition of diets such as lacking fruit and vegetable consumption, high intake of sugary beverages and snacks have eliminated the previous traditional plant-based foods which eventually led to poor nutritional outcome such as obesity (Soo, Manan, Manaf, \& Lee, 2011). In term of dietary assessment, standard dietary methods frequently used in evaluating dietary intakes include a 24-hour dietary recall, food record and food frequency questionnaire (FFQ) (Norimah, 2012). Existing tools have few limitations, a 24-hour dietary recall or food records method were considered impractical due to feasibly issues and cost associated with scheduling, training interviewer or respondent and coding data for sizeable observational study (Park et al., 2018).

eISSN: 2398-4287 C 2019. The Authors. It is published for AMER ABRA cE-Bs by e-International Publishing House, Ltd., UK. This is an open-access article under the CC BYNC-ND license (http://creativecommons.org/licenses/by-nc-nd/4.0/). Peer-review under responsibility of AMER (Association of Malaysian Environment-Behaviour Researchers), ABRA (Association of Behavioural Researchers on Asians) and cE-Bs (Centre for Environment-Behaviour Studies), Faculty of Architecture, Planning \& Surveying, Universiti Teknologi MARA, Malaysia.

DOI: https://doi.org/10.21834/e-bpj.v4i12.1909 
Furthermore, both methods were focusing on short-term intake. Even though FFQ has the strength of querying about long-term intake, but its imprecision and cognitive difficulty to memorise is still questionable (Carroll et al., 2012). Misreporting includes both underreporting and over-reporting is a common occurrence during the dietary assessment due to food or beverage additions, omissions or substitutions, or may arise through inaccurate portion size estimation and variations in individual self-report of their intake (Forrestal, 2011).

Several food-frequency tools and nutrient-specific food frequency tools developed to assess nutrient intakes in children and adults. For instance, a self-administered, semi-quantitative FFQ consisting of 94 food items and 12 food groups, was developed for Malaysian school-aged children to assess habitual diets of multi-ethnic (Fatihah et al., 2015). In Malaysia, there was a study to establish FFQ focusing on the intake of added sugar evaluated among adult in Klang Valley, Malaysia (Norimah, 2012). However, adult-based tools would not be appropriate for large-scale evaluations of school-based dietary behaviours because of the length of the questionnaire, limited reliability and lack of specificity toward foods addressed by school policies (Cullen, Watson, \& Zakeri, 2008). As part of the Policy Legislation and Nutrition, a study conducted to tailor for school nutrition policies in Seattle, WA. The Beverages and Snacks Questionnaire developed to investigate the frequency intake and location of intake (either at school or away from school) of soft drink, salty snack, sweets, milk, fruit and vegetables (Neuhouser, Lilley, Lund, \& Johnson, 2009). However, there is no available FFQ for the Malaysian population individually to assess beverage and snack intake among schoolchildren. Therefore, this study has determined to develop and validate beverages and snacks questionnaire (BSQ-C) to evaluate behaviour and pattern of sugar-sweetened beverages (SSBs), and snacks intake among young schoolchildren in Kelantan, Malaysia.

\subsection{Literature Review}

Energy intake from sugar-sweetened beverages (SSBs) increased by 135\% between 1977 and 2001 in all age groups (Nielsen \& Popkin, 2004). Globally, consumption of SSBs has been growing progressively because of rapid urbanisation and heavy marketing in low- and middle-income countries (Yngve, Haapala, Hodge, McNeill, \& Tseng, 2012). In analysing food supply and economics, increased the availability of SSBs and process foods in packages attributed to a few multinational corporations who have domestic production in many nations (Basu, 2015). Snacks and fast foods consumption contribute to the development of childhood obesity (Anuar Zaini, Lim, Low, \& Harun, 2005). High intake of SSBs also has been associated with a higher risk of kidney stone formation (Ferraro, Taylor, Gambaro, \& Curhan, 2013). Meanwhile, high consumption of fructose in SSBs is strongly associated with decreased insulin sensitivity, high dyslipidaemia and visceral adiposity in overweight adults (Welsh, Lundeen, \& Stein, 2013).

Factors influencing SSBs consumption are related to advertising and marketing, price, taste and availability (Grimm, Harnack, \& Story, 2004). Besides, SSB consumption is associated with a less healthy dietary pattern such as frequent fast-food meals, lower intakes of healthy beverages, breakfast skipping; and TV watching among children and adolescents (Mathias, Slining, \& Popkin, 2013). Mostly, adolescent and young adults reported higher consumption of SSBs than younger children and older adults. According to studies conducted in Korean, higher intake of SSBs associated with higher socioeconomic status (Kim, Park, \& Oh, 2013). Several studies have measured the relationship between sweetened beverages intake and health problems (Malik, Schulze, \& Hu, 2006). Besides, there was a study that identified the trend of canned drinks and its associated factors that influence and its relation to the sugar intake among Malaysian adolescent (Radzi, Ying, Kiat, Kazemipoor, \& Jamungi, 2013). However, unfortunately, there is insufficient evidence to indicate an estimation of intake levels of added sugar among different age groups among Malaysian, or identification of significant sources of added sugar (Amarra, Khor, \& Chan, 2016). The number of studies related to food choices among young children reported in Malaysia (Ishak, Zainun, Shohaimi, \& Kandiah, 2013), in particular in term of sugar-sweetened beverages (SSBs) and snacks among schoolchildren are still lacking. .

Several instruments have existed to assess beverages consumption; however, the tools have few limitations in assessing SSBs and snacks intake among children. The beverage intake questionnaire was used by Tengs and colleagues to measure the consumption of plain water and SSB and its association with body mass index (BMI) among undergraduate students in a Malaysian university. The questionnaire was adapted and modified from a study by Hedrick et al. (Teng, Nordin, Suraya, \& Shah, 2019). However, the tool was developed explicitly for adult, not for schoolchildren population (Hedrick, Comber, Estabrooks, Savla, \& Davy, 2010). Another study in Selangor, Malaysia, was purposely conducted to determine the amount of SSBs consumption and its associated factors among adolescent. However; the questionnaire did not measure the consumption of SSBs based on vendor-made or home-prepared drinks and also snacks (Gan, Mohamed, \& Law, 2019). Therefore, based on this Malaysian literature, a research gap has been addressed, and this study aimed to develop and validate Beverages and Snacks Questionnaire for Malaysian Schoolchildren (BSQ-C).

\subsection{Methodology}

The development and validation of the Beverages and Snacks Questionnaire for Schoolchildren (BSQ-C) were both conducted before the subsequent used in a cross-sectional study among schoolchildren. This paper attempt to highlight the protocol of the development and validation of BSQ-C only. The process consisted of three stages: (a) to identify beverages and snacks frequently consumed by our schoolchildren, (b) development of the BSQ-C, (c) pilot testing and estimation of the internal consistency of the BSQ-C.

\subsection{Recruitment of participants}

Ninety-nine participants of schoolchildren aged 10 to 11 years old, enrolled primary school in Kota Bharu, Kelantan, Malaysia were selected through random sampling method. Before the data collection, schoolchildren were explained about the purpose of the study. 
Parents/ guardians were informed by the researchers regarding the aim and protocol of the study before they consented and gave the approval to let their children participate in the study. Ethical approval of the study was obtained from the Universiti Sultan Zainal Abidin Human Research Ethics Committee (UniSZA/UHREC/2018/40).

\subsection{Development of the BSQ-C}

To develop this new questionnaire, literature review search regarding the instrument to assess sugar-sweetened beverages (SSBs) and snacks was performed. The purpose of the literature search was for categorisation of the type of SSBs into few groups; groups of fruit juice and fruit drinks; milk and cultured milk drinks; carbonated beverages; chocolate malt, tea, and coffee; instant drinks; vendor-made drinks. Whereas snack groups were categorised into; biscuit; cake; chocolate; and jelly. In this study, to identify the most frequent type of SSBs and snacks consumed by schoolchildren, a $24 \mathrm{~h}$ dietary recall method was performed. Finally, 61 items commonly consumed SSBs and snacks were derived to form a BSQ-C. All SSBs and snacks identified were then analysed in the laboratory for the sugar composition analyses. All those items were converted into a food album to assist during data collection in the classroom.

The initial BSQ-C was pretested among schoolchildren $(n=35)$ for the clarity and its appropriateness of the target population. Apart from its clarity, the feasibility of response format was taken into account, including specific food categories and the understanding or feedback from schoolchildren on the coding items towards food album. Food album which contained information and photographic visual of the SSBs and snacks was used to assist the schoolchildren in reporting the frequency intake of SSBs and snacks. Schoolchildren were asked to list down other SSBs and snacks item which were not listed in the food album and BSQ-C. SSBs and snacks item recorded by two-third of the schoolchildren were considered as frequent. A multiple-pass $24 \mathrm{~h}$ dietary recall consisted one weekend and two weekdays also was completed by schoolchildren during the pretesting period. Changes and adaptation of the BSQ-C were implemented, including the response format, type of food category, and numbers of list item of beverages and snacks consumed daily. The revised BSQ-C contained 18 removed and an additional 14 types of beverages and snacks. Removal or addition of items was based on the feedback on the BSQ-C and comparison with 24-h dietary recall recorded. The draft of BSQ-C comprised of 57 items with ten questions about fruit drink; milk and cultured milk; carbonated drink; chocolate malt, tea, and coffee; home-made drink; vendor-made beverages; biscuit; cake and bread; chocolate; and confectionery. The number of questions remained, but there was an adaptation of the category of SSBs and snacks item.

\subsection{Pilot testing and estimation of the internal consistency of the final draft of BSQ-C}

The final draft of BSQ-C was finally pretested and repeated for the second time among 99 schoolchildren at different school. The internal consistency of the questions was loaded onto the same variables and checked using the Cronbach's alpha to indicate the correlation between the items. Based on the analysis indicated by Cronbach's alpha below than 0.70 , few changes have been made to the questionnaire. Three categories of SSBs such as malt chocolate, tea and coffee; home-made drinks; cake and bread were deleted. However, all the other items were merged or remain to keep into a suitable category. The final BSQ-C comprised of 57 items and sevenquestions only. Ninety-nine schoolchildren were interviewed regarding their frequency of intake on fruit drinks; milk and cultured milk drinks; carbonated drinks; vendor-made or home-prepared drinks; biscuits; chocolate; and confectionery categories, apart from the amount and location during their intake.

\subsection{Data analysis}

Statistical analysis was performed in data analysis using the Statistical Package for Social Sciences (SPSS) version 24. The internal consistency was analysed to get Cronbach's alpha coefficients and item-total correlation for each variable.

\subsection{Findings}

\subsection{Contents of the questionnaire}

Table 1 shows the seven questions with 57 responses of the newly developed BSQ-C, asking about the frequency of SSBs or snacks intake over for the last one week as an average. The seven-question divided into fruit drinks, milk and cultured milk drinks, carbonated drinks, vendor-made or home-prepared drinks, biscuits, chocolate and confectionery category.

Table 1: Contents of Beverages and Snacks Questionnaire for Schoolchildren (BSQ-C).

\begin{tabular}{clc}
\hline $\begin{array}{c}\text { Question } \\
\text { number }\end{array}$ & Question & Response \\
\hline 1 & Over the last week, on average, how often to drink fruit drink? & 8 \\
2 & Over the last week, on average, how often to drink milk and cultured milk drinks? & 10 \\
3 & Over the last week, on average, how often to drink carbonated drink? & 4 \\
4 & Over the last week, on average, how often to drink vendor-made/ home-prepared drink? & 12 \\
5 & Over the last week, on average, how often to eat biscuits? & 7 \\
6 & Over the last week, on average, how often to eat chocolate? & 6 \\
7 & Over the last week, on average, how often to eat confectionery? & 10 \\
\hline
\end{tabular}

\subsection{Internal consistency reliability}


The Cronbach's alpha calculated to gain the internal consistency of the revised BSQ-C. The internal consistency reliability indicated how well the items fit together conceptually and examined the inter-item correlation within the instrument (DeVon et al., 2007). The itemtotal correlation and Cronbach's alpha for all items and variables of the developed BSQ-C indicated in Table 2. If the value of item-total correlation, more than 0.30 indicate, the item was fit to the appropriate variable. However, chocolate malt, hot chocolate, gummy and ice-cream were below than 0.30 . Nevertheless, those items were retained in the questionnaire as the Cronbach's alpha value was acceptable.

Table 2: Reliability analysis of items on fruit drinks, milk and cultured milk drinks, carbonated drinks, vendor-made drinks, biscuits, chocolate and confectionery. $(n=99)$

\begin{tabular}{|c|c|c|c|c|}
\hline \multirow[b]{2}{*}{ Variables } & \multirow[b]{2}{*}{ Items } & \multicolumn{3}{|c|}{ Internal consistency } \\
\hline & & $\begin{array}{c}\text { Corrected item-total } \\
\text { correlation }\end{array}$ & Alpha if item deleted & Cronbach's alpha \\
\hline \multirow[t]{8}{*}{ Fruit drinks } & Apple drink & 0.54 & 0.67 & 0.73 \\
\hline & Orange drink & 0.44 & 0.70 & \\
\hline & Blackcurrant drink & 0.52 & 0.68 & \\
\hline & Soy drink & 0.31 & 0.72 & \\
\hline & Mango drink & 0.49 & 0.69 & \\
\hline & Lychee drink & 0.37 & 0.71 & \\
\hline & Ice lemon tea & 0.40 & 0.70 & \\
\hline & Chrysanthemum & 0.31 & 0.72 & \\
\hline \multirow{10}{*}{$\begin{array}{l}\text { Milk and cultured milk } \\
\text { drinks }\end{array}$} & Strawberry flavoured & 0.48 & 0.74 & 0.77 \\
\hline & Fresh & 0.44 & 0.75 & \\
\hline & Chocolate flavoured & 0.61 & 0.72 & \\
\hline & Full cream & 0.48 & 0.74 & \\
\hline & Flavour cultured & 0.33 & 0.76 & \\
\hline & Plain cultured & 0.46 & 0.74 & \\
\hline & Yogurt & 0.35 & 0.76 & \\
\hline & Yogurt drink & 0.48 & 0.74 & \\
\hline & Latte & 0.40 & 0.75 & \\
\hline & Chocolate malt* & 0.29 & 0.77 & \\
\hline \multirow[t]{4}{*}{ Carbonated drinks } & Cola & 0.33 & 0.75 & 0.71 \\
\hline & Orange & 0.62 & 0.57 & \\
\hline & Strawberry & 0.69 & 0.52 & \\
\hline & Isotonic & 0.39 & 0.71 & \\
\hline \multirow{12}{*}{$\begin{array}{l}\text { Vendor-made/ home- } \\
\text { prepared drinks }\end{array}$} & Bandung & 0.59 & 0.77 & 0.80 \\
\hline & Jagung & 0.43 & 0.78 & \\
\hline & Ice chocolate & 0.40 & 0.78 & \\
\hline & Lychee & 0.62 & 0.76 & \\
\hline & Ice tea & 0.38 & 0.79 & \\
\hline & Ice milk tea & 0.36 & 0.79 & \\
\hline & Asam boi & 0.58 & 0.77 & \\
\hline & $A B C$ & 0.45 & 0.78 & \\
\hline & Hot tea & 0.39 & 0.79 & \\
\hline & Orange concentrated & 0.48 & 0.78 & \\
\hline & Rose syrup & 0.34 & 0.79 & \\
\hline & Hot chocolate ${ }^{*}$ & 0.26 & 0.80 & \\
\hline \multirow[t]{7}{*}{ Biscuits } & Chocolate chips & 0.46 & 0.71 & 0.74 \\
\hline & Cheese sandwich & 0.54 & 0.69 & \\
\hline & Plain biscuit & 0.53 & 0.69 & \\
\hline & Peanut butter sandwich & 0.49 & 0.71 & \\
\hline & Chocolate cream biscuit & 0.39 & 0.73 & \\
\hline & Chocolate biscuit & 0.35 & 0.73 & \\
\hline & Chocolate stick & 0.46 & 0.71 & \\
\hline \multirow[t]{6}{*}{ Chocolate } & Chocolate rice cereal & 0.37 & 0.68 & 0.70 \\
\hline & Wafer bar & 0.35 & 0.69 & \\
\hline & Milk chocolate coated & 0.52 & 0.64 & \\
\hline & Milk chocolate coated wafer & 0.46 & 0.65 & \\
\hline & Chocolate nugget & 0.46 & 0.65 & \\
\hline & Chocolate bar & 0.44 & 0.66 & \\
\hline \multirow[t]{7}{*}{ Confectionery } & Candy & 0.35 & 0.69 & 0.71 \\
\hline & Gummy* & 0.29 & 0.70 & \\
\hline & Jelly & 0.41 & 0.68 & \\
\hline & Lollipop & 0.40 & 0.68 & \\
\hline & Layer cake & 0.36 & 0.68 & \\
\hline & Cream bread & 0.37 & 0.68 & \\
\hline & Cake & 0.40 & 0.68 & \\
\hline
\end{tabular}




\begin{tabular}{llcc}
\hline \multirow{2}{*}{\begin{tabular}{l} 
Items \\
\cline { 2 - 3 }
\end{tabular}} & $\begin{array}{c}\text { Corrected item-total } \\
\text { correlation }\end{array}$ & Alpha if item deleted \\
& Chocolate spread & 0.45 & 0.67 \\
& Chocolate coated wafer & 0.52 & 0.66 \\
& Ice cream & 0.12 & 0.72 \\
\hline
\end{tabular}

The Cronbach's alpha reliability coefficients for fruit drinks, milk and milk cultured drinks, carbonated drinks, vendor-made/ homeprepared beverages, biscuits, chocolate and confectionery were $0.73,0.77,0.71,0.80,0.74,0.70$, and 0.71 , respectively (Figure 1 ). The value of Cronbach's alpha of 0.70 indicated that the item is acceptable for a newly developed instrument. The closer the Cronbach's alpha value to 1.00, the higher the internal consistency in the scale (Gliem \& Gliem, 2003). The total value of Cronbach's alpha for the overall newly developed BSQ-C was 0.94 , which indicated a high correlation between the items and consistently reliable to use in the population survey.

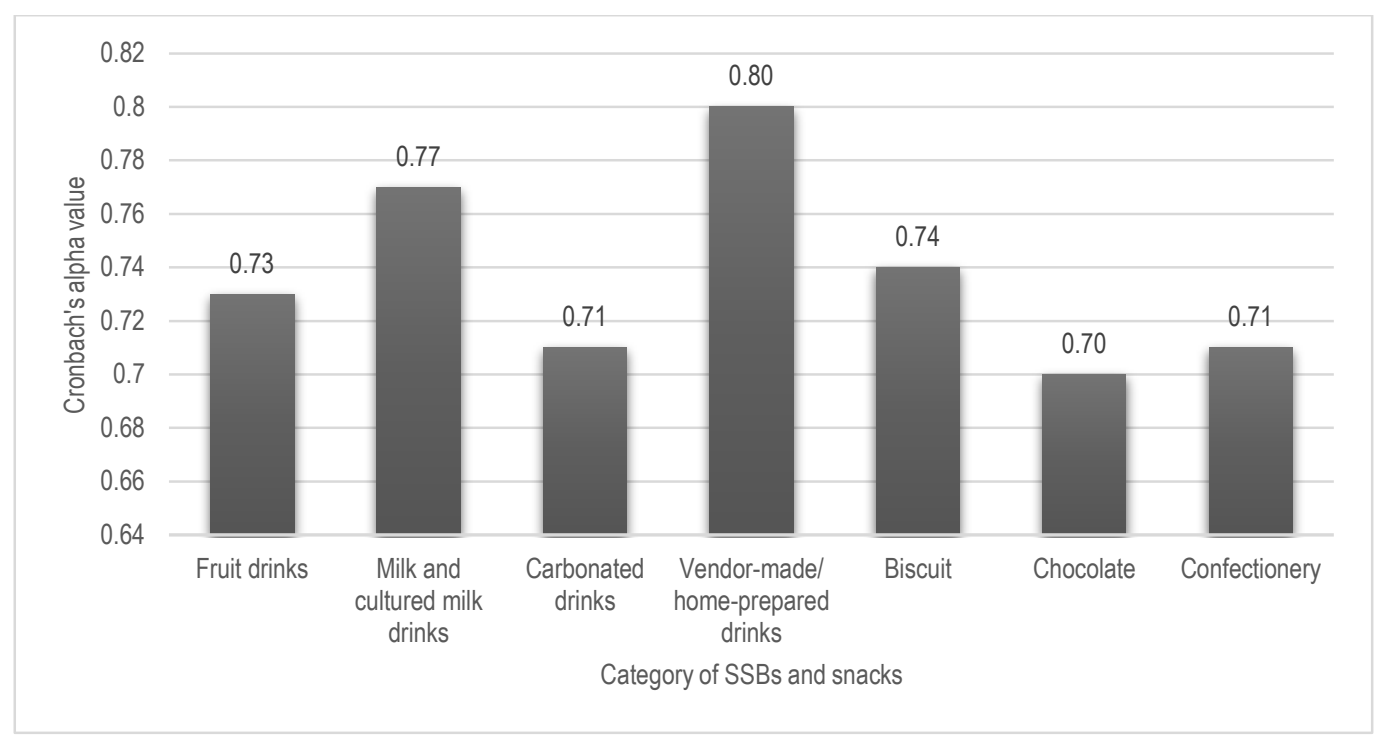

Figure 1: The Cronbach's alpha reliability coefficients value for each category of SSBs and snacks

\subsection{Discussion}

\subsection{Contents and internal consistency of the newly developed BSQ-C}

This brief, guided-questionnaire was useful for assessing SSBs and snacks intake among schoolchildren aged 10 to 11 years old. The least number of seven questions of BSQ-C was practical and ethical in reducing the burden of respondents, in particular, young children. It is also very brief, simple, useful and valid to use during the population-based survey. Furthermore, the BSQ-C was quickly to comprehend and reliable to utilise within the reasonable time allocated by school authorities for data collection during schooling hours. The items in this questionnaire represented the typical and frequent consumption of SSBs and snacks among schoolchildren. Food album used to assist the schoolchildren while answering the frequency of intake SSBs and snacks were very helpful and beneficial during data collection as the respondents were young schoolchildren. All photos of SSBs and snacks in the food album were accompanied with serving size, to assist schoolchildren in reporting the volume of SSBs and amount of snacks intake. Also, schoolchildren completed the location intake of SSBs and snacks in the BSQ-C.

During the pilot testing and estimation of internal consistency of the BSQ-C, for malt chocolate, tea and coffee drinks; home-made drink; cake and bread; chocolate and confectionery were below of 0.70 Cronbach's alpha value. Lacking of items in the scale contributed to the low score observed for correlation between the items (Grummon et al., 2017). However, to increase the reliability of BSQ-C, items with item-total correlation below 0.30 were reorganised and rearrange towards the possible category without omitting the relevant content. Eventually, the revised BSQ-C shows increases in the value of Cronbach's alpha and acceptable internal consistency. Increasing of Cronbach's alpha value would be achieved by adding more items and the items provided were correlated to each other (DeVellis, 2016). Based on the results of the item-total correlation, four items showed values less than 0.30; chocolate malt (0.29), hot chocolate (0.26), gummy (0.29), and ice-cream (0.12). However, all the items remained in the BSQ-C as the Cronbach's alpha value was acceptable. Internal consistency of BSQ-C was assessed using Cronbach's alpha for sub and overall variables. The internal consistency for the whole in this BSQ-C obtained was very high, with a Cronbach's alpha of 0.94 . Rules of thumb provided, Cronbach's alpha value more than 0.90 was excellent (Mallery \& George, 2003). However, in some study mention that Cronbach's alpha value over 
0.90 represents redundancies and the tool should be shortened, but that redundancy was necessary to internal consistency (DeVellis, 2016).

\subsection{BSQ-C}

Results from this study indicated that the BSQ-C was a valid and reliable tool to measure beverages and snacks intake among schoolchildren aged 10 to 11 years old in Kelantan, Malaysia. The strength of this study includes the production of SSBs and snacks food album accompanied by the BSQ-C and identification of the location of intake, which may influence the nutrition policy for environment intervention. In other words, SSBs and snacks food album produced in this study would be beneficial in assisting schoolchildren in assessing their intake in future studies regarding SSBs and snacks consumption. However, the study was limited only to SSBs and snacks frequently consumed in Kelantan, Malaysia but not able to represent for the whole schoolchildren in Malaysia. Kelantan is one of the northeast states in Peninsular Malaysia, where the dietary pattern is heterogeneous compared to other 12 states in Malaysia. Furthermore, this study also was conducted in the urban area of the capital city so-called Kota Bharu and did not cover other rural areas in Kelantan. In term of age factor, only those schoolchildren aged 10 to 11 years participated in this study. The objective to develop this specific BSQ-C has achieved as there is no brief questionnaire available to assess SSBs and snacks consumption among young schoolchildren. Although other instruments were available for assessment of beverages and snacks in adolescent (De Cock et al., 2017; Neuhouser et al., 2009), this newly developed instrument provided a practical way to collect information specifically on SSBs and snacks consumption among schoolchildren.

\subsection{Conclusion \& Recommendations}

In this present study, a BSQ-C was a useful tool for assessing the type, amount and location intake of some of the SSBs and snacks commonly consumed by schoolchildren, including fruit drinks; milk and cultured milk drinks; carbonated drinks; vendor-made or homeprepared drinks, biscuits; chocolate; and confectionery. This pioneering work of BSQ-C tool has the potential to be utilised for other cross-sectional studies nationwide, Malaysia in particular, to evaluate the consumption of SSBs and snacks among schoolchildren. Future research could improvise the items accordingly to the culturally-specific of local food and beverages.

\section{Acknowledgement}

The Sumitomo Foundation has fully supported this study in term of financial assistance. Special thanks to Asian Nutrition and Food Culture Research Centre for their technical support. Special thanks go to the Ministry of Education, Malaysia, who approved this study protocol, all school teachers involved in this study, schoolchildren as respondents and their respective parents. Our gratitude also goes to the enumerators who assisted during the data collection.

\section{References}

Amarra, M. S. V., Khor, G. L., \& Chan, P. (2016). Intake of added sugar in Malaysia: a review. Asia Pacific Journal of clinical nutrition, 25(2), 227-240.

Anuar Zaini, M., Lim, C., Low, W., \& Harun, F. (2005). Factors affecting the nutritional status of Malaysian primary school children. Asia Pacific Journal of Public Health, 17(2), 71-80.

Basu, S. (2015). The transitional dynamics of caloric ecosystems: changes in the food supply around the world. Critical public health, 25(3), 248-264.

Carroll, R. J., Midthune, D., Subar, A. F., Shumakovich, M., Freedman, L. S., Thompson, F. E., \& Kipnis, V. (2012). Taking advantage of the strengths of 2 different dietary assessment instruments to improve intake estimates for nutritional epidemiology. American journal of epidemiology, 175(4), 340-347.

Cullen, K. W., Watson, K., \& Zakeri, I. (2008). Relative reliability and validity of the Block Kids Questionnaire among youth aged 10 to 17 years. Journal of the American Dietetic Association, 108(5), 862-866.

De Cock, N., Van Camp, J., Kolsteren, P., Lachat, C., Huybregts, L., Maes, L., . . Beullens, K. (2017). Development and validation of a quantitative snack and beverage food frequency questionnaire for adolescents. Journal of human nutrition and dietetics, 30(2), 141-150.

DeVellis, R. F. (2016). Scale development: Theory and applications (Vol. 26): Sage publications.

DeVon, H. A., Block, M. E., Moyle-Wright, P., Ernst, D. M., Hayden, S. J., Lazzara, D. J., . . Kostas-Polston, E. (2007). A psychometric toolbox for testing validity and reliability. Journal of Nursing Scholarship, 39(2), 155-164.

Dunford, E., \& Popkin, B. (2018). 37-year snacking trends for US children 1977-2014. Pediatric Obesity, 13(4), $247-255$.

Fatihah, F., Ng, B. K., Hazwanie, H., Norimah, A. K., Shanita, S. N., Ruzita, A. T., \& Poh, B. K. (2015). Development and validation of a food frequency questionnaire for dietary intake assessment among multi-ethnic primary school-aged children. Singapore medical journal, 56(12), 687.

Ferraro, P. M., Taylor, E. N., Gambaro, G., \& Curhan, G. C. (2013). Soda and other beverages and the risk of kidney stones. Clinical Journal of the American Society of Nephrology, 8(8), 1389-1395.

Forrestal, S. G. (2011). Energy intake misreporting among children and adolescents: a literature review. Maternal \& child nutrition, 7(2), $112-127$. 
Gan, W. Y., Mohamed, S. F., \& Law, L. S. (2019). Unhealthy Lifestyle Associated with Higher Intake of Sugar-Sweetened Beverages among Malaysian School-Aged Adolescents. International journal of environmental research and public health, 16(15), 2785.

Gliem, J. A., \& Gliem, R. R. (2003). Calculating, interpreting, and reporting Cronbach's alpha reliability coefficient for Likert-type scales.

Grimm, G. C., Harnack, L., \& Story, M. (2004). Factors associated with soft drink consumption in school-aged children. Journal of the American Dietetic Association, 104(8), 1244-1249.

Grummon, A. H., Hampton, K. E., Hecht, A., Oliva, A., McCulloch, C. E., Brindis, C. D., \& Patel, A. I. (2017). Validation of a brief questionnaire against direct observation to assess adolescents' school lunchtime beverage consumption. Journal of nutrition education and behaviour, 49(10), 847-851. e841.

Hedrick, V. E., Comber, D. L., Estabrooks, P. A., Savla, J., \& Davy, B. M. (2010). The beverage intake questionnaire: determining initial validity and reliability. Journal of the American Dietetic Association, 110(8), 1227-1232.

Ishak, S., Zainun, S. I., Shohaimi, S., \& Kandiah, M. (2013). Assessing the children's views on foods and consumption of selected food groups: outcome from a focus group approach. Nutrition Research and Practice, 7(2), 132-138.

Kim, K., Park, S. M. \& Oh, K. W. (2013). The impact of nutritional policy on the socioeconomic disparity in the unhealthy food intake among Korean adolescents. Appetite 71, 388-395.

Malik, V. S., Schulze, M. B., \& Hu, F. B. (2006). Intake of sugar-sweetened beverages and weight gain: a systematic review. The American journal of clinical nutrition, 84(2), 274-288.

Mallery, P., \& George, D. (2003). SPSS for Windows step by step: a simple guide and reference. Allyn, Bacon, Boston.

Mathias, K. C., Slining, M. M., \& Popkin, B. M. (2013). Foods and beverages associated with higher intake of sugar-sweetened beverages. American journal of preventive medicine, 44(4), 351-357.

Neuhouser, M. L., Lilley, S., Lund, A., \& Johnson, D. B. (2009). Development and validation of a beverage and snack questionnaire for use in the evaluation of school nutrition policies. Journal of the American Dietetic Association, 109(9), 1587-1592.

Nielsen, S. J., \& Popkin, B. M. (2004). Changes in beverage intake between 1977 and 2001. American journal of preventive medicine, 27(3), 205-210.

Norimah, A. (2012). Development and validation of a Food Frequency Questionnaire (FFQ) for assessing sugar consumption among adults in Klang Valley, Malaysia. Malaysian Journal of Nutrition, 18(3).

Park, Y., Dodd, K. W., Kipnis, V., Thompson, F. E., Potischman, N., Schoeller, D. A., . . Bowles, H. (2018). Comparison of self-reported dietary intakes from the Automated Self-Administered 24-h recall, 4-d food records, and food-frequency questionnaires against recovery biomarkers. The American journal of clinical nutrition, 107(1), 80-93.

Radzi, C. W. J. W. M., Ying, P. L., Kiat, P. E., Kazemipoor, M., \& Jamungi, A. Z. (2013). Sugar Consumption: Case Study on Adolescents' Canned Drinks Intake. Advanced Science Letters, 19(10), 2974-2978

Soo, K., Manan, W., Manaf, H. A., \& Lee, Y. (2011). Dietary practices among overweight and obese Chinese children in Kota Bharu, Kelantan. Malaysian Journal of Nutrition, 17(1).

Teng, N. I. M. F., Nordin, N. J., Suraya, A., \& Shah, M. (2019). Plain water and beverage consumption patterns among university students in Puncak Alam, Malaysia. Peer-reviewed Journal of the Nutrition Society of Malaysia, 25(2), 227.

Welsh, J. A., Lundeen, E. A., \& Stein, A. D. (2013). The sugar-sweetened beverage wars: public health and the role of the beverage industry - current opinion in endocrinology, diabetes, and obesity, 20(5), 401.

Yngve, A., Haapala, I., Hodge, A., McNeill, G., \& Tseng, M. (2012). Making soft drinks the dietary version of the cigarette. Public health nutrition, 15(8), 1329. 